\title{
Dynamic Model and Analysis of a Sucker-rod Pump Injection-production System
}

\author{
Jiang MINZHENG, Zhang DESHI, Feng ZI-MING, Duan TIANYU
}

\begin{abstract}
Injection and production at the same oil well is an effective way to achieve stable production and control water-cut. A sucker-rod pump injection-production system is composed of a production pump, piston seal, injection pump, and so on. It separates oil and water down the well hole using gravity, then injects the water directly into the formation while the concentrated oil is brought to the surface. To explore the complex forces involved in the system, static and dynamic models of the injection pump, sealed piston and production pump are established from the bottom up based on the mechanical method, and a solution is established using the difference method. Finally, a dynamic simulation of the system is compiled in Visual Basic V6.0, and the correctness and practicality of the simulation are verified by field measurements.
\end{abstract}

Keywords: dynamic model; injection-production system; Gibbs model; sucker-rod pump

\section{INTRODUCTION}

At present, many oilfields in China have entered the stage of high water cut, and the water cut of produced liquid has increased year by year. For example, the average water cut of some old onshore oilfields in China has reached $90 \%$ [1]. High water cut leads to increased production costs and has forced some oilfields to be scrapped; even though many still contain large amounts of unexploited crude oil, which causes a great deal of waste. At the same time, the treatment of produced water can cause environmental pollution problems $[2,3]$.

To maintain long-term, effective, high and stable production, a new oil recovery technology has emerged that uses injection and production technology in the same well $[4,5]$. This technology includes a lifting system and a downhole oil-water separation system. Most of the water is separated and injected into the reservoir formation, while the separated concentrate (produced liquid with less water than prior to separation) is raised to the surface. The two processes of oil recovery and water injection are completed at the same time in the same wellbore $[6,7]$. This process not only successfully reduces the water cut of the produced liquid and saves much cost, it also improves recovery efficiency. This process can also allow abandoned reservoirs to be redeveloped economically and effectively, thus increasing production and recovery efficiency and reducing environmental impacts [8].

In the 1990s, the Canadian C-FER first put forward the idea of downhole oil-water separation and put it to use [912]. Since then, the system of injection and production at the same well has been successfully applied in many oilfields around the world. Downhole testing of such 'injection- production' systems has been carried out in Daqing oilfield, China, with good results. The lifting equipment can include sucker-rod pumps, progressing cavity pumps, electrical submersible pumps, and so on [1316]. The Texas Company uses a dual-action pump to produce oil and water at the same time, but oil and water are not separated effectively [17, 18]. Yan Tingjun [19] proposed a design for an oil-water separation system using a downhole electric submersible pump, but the price of the pump is 23 times higher than that of a conventional electric submersible pump. Zhou Xiaojun [20] designed a reciprocating double-flow pump that produces significant precipitation and oil stability. However, the pump has a complicated structure and a large cross-sectional size.

In 1963, Gibbs [21] presented a sucker-rod load calculation method that was suitably generalized for a wide range of applications. Many companies, such as the Lufkin Foundry and Machine Company, used Gibbs' method in commercial service by implementing sucker-rod pump analysis. Chacin and Purcupile [22] modified the rod string to become a spring-mass system with damping, and established ordinary differential equations to describe the lumped mass element vibration law. They established a system model based on the numerical integral method. In 1983, Doty and Schmidt [23] established a twodimensional model of the coupled vibration of the rod string and liquid column.

In 2015, Ferrigno et al. [24] proposed an algorithm that uses a combination of motor performance analysis and calculations based on API 11E. It allows determination of the real torque of units in real-time from telemetry, eliminating the need to make on-site surveys of the counterweighting of the unit.

In 2016, Lao and Zhou [25] developed a method that directly calculates the fluid force acting on the curved cylindrical surface of the rod element. They used the pump dynamometer cards as a boundary condition and solved wave equations for sucker-rod pumping more accurately than was previously possible. In 2016 , by considering the limitations of models of deep and ultra-deep wells, Xing [26] developed an improved model for a sucker-rod pumping system. In 2018, Feng et al. [27] modelled a 3Dwave coupling dynamic function for the sucker-rod, tube and fluid column and simulated it in Visual Basic V6.0. However, there are no suitable dynamic functions built for injection-production systems.

The pump has a complex structure and large sectional size; therefore, a static and dynamic modelling framework is needed for the design of injection-production systems. According to the oil-water separation system used, the injection-production systems can be divided into two types: gravity separation and mechanical separation. In this design, a gravity multi-cup equal-flow separator (a type of oil-water pump) is used that has a simple structure and does not need a power drive. Two sets of double-plunger pumping pumps are used to achieve oil production and water injection in a sucker-rod pump injection-production system. This is consistent with the main exploitation mode 
used in pumping units in China. Field applications have achieved improved dewatering and demonstrated good development prospects.

\section{STRUCTURE AND WORKING PRINCIPLES OF SUCKER-ROD PUMP INJECTION-PRODUCTION SYSTEMS}

\subsection{Structure of a Sucker-rod Pump Injection-production} System

Sucker-rod pump injection-production systems are mainly composed of a conventional beam pumping unit, a production pump, a sealed piston, a bridge packer, an injection pump and an oil-water separation system, as shown in Fig. 1.

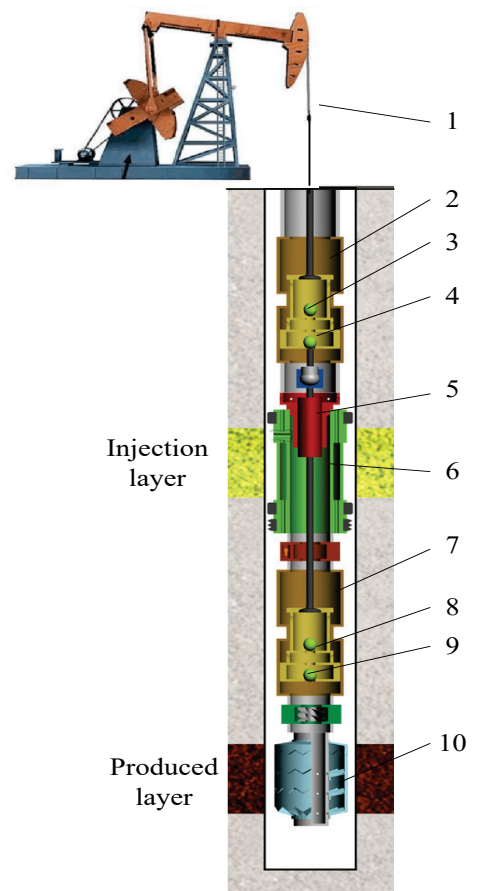

Figure 1 Diagram of a sucker-rod pump injection-production system. Legend: 1conventional beam pumping unit, 2- production pump, 3- upper valve of production pump, 4- Lower valve of production pump, 5- sealed piston, 6- bridge packer, 7-injection pump, 8- Upper valve of injection pump, 9- lower valve of injection pump, 10 - oil-water separator.

\subsection{Working Principle of the Sucker-Rod Pump Injection- Production System}

After oil enters the settling cup of the oil-water separator, the fluid produced after entering the settling cup is divided into two layers within a very short time because of the action of gravity. That is, the water has higher density and the oil with low water cut has lower density. The lower layer of water flows through the central pipe of the oil-water separator to the suction inlet of the injection pump and circulates back into the injected layer, while the upper layer of concentrated oil flows up through the middle channel to the suction port of the pump and rises to the surface.

(1) As shown in Fig. 2, when the pump plunger is driven by the rod, the volume of the pump's inner ring cavity 2 is reduced, lower valve 2 is closed, upper valve 2 is opened, and the liquid from pump inner ring cavity 2 is discharged into the injection chamber and injected into the injection layer; at the same time, the pump plunger goes up synchronously and the liquid in pump inner ring cavity 1 is discharged and lifted to the surface, which completes the process of oil recovery and injection back.

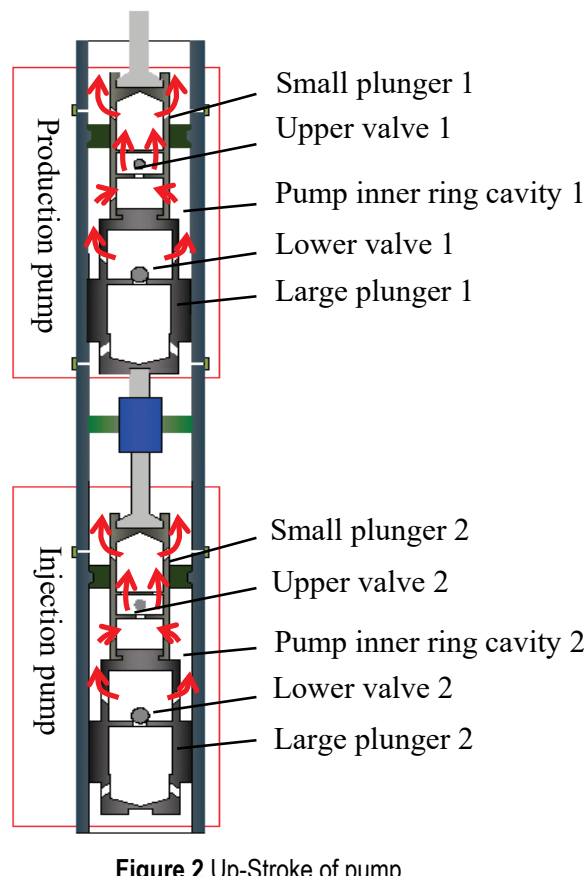

(2) As shown in Fig. 3, in the lower stroke, the plunger of the injection pump goes down with the sucker-rod, the volume of inner ring cavity 2 increases, lower valve 2 opens, upper valve 2 closes, the water separated by the oilwater separator is drawn into the inner ring cavity of the pump, the pump plunger is pulled down at the same time, and the concentrated liquid separated by the oil-water separator is drawn into the bridge packer channel. In inner ring 1 of the pump, the injection pump and production pump simultaneously complete the processes of water absorption and oil absorption after oil-water separation.

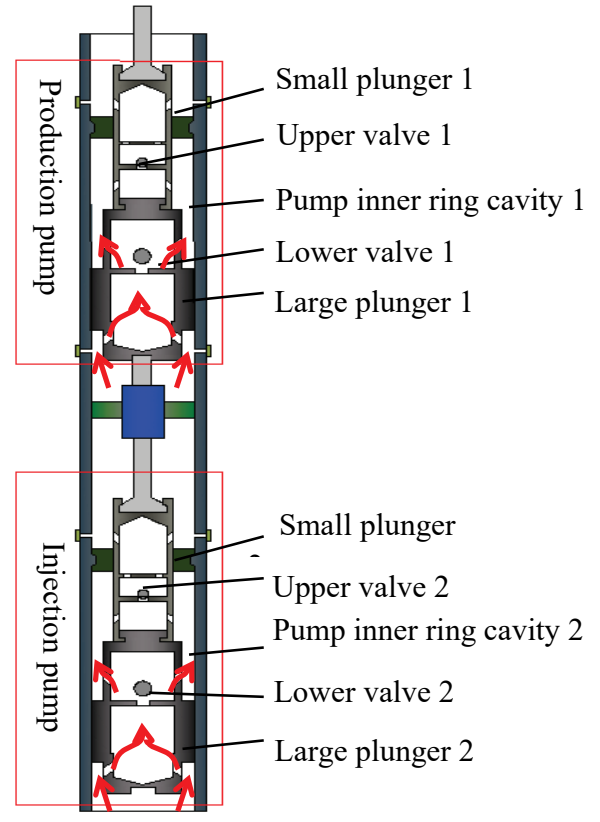

Figure 3 Down-stroke of pump 


\section{STATICS ANALYSIS OF THE ROD STRING IN THE SUCKER-ROD PUMP INJECTION-PRODUCTION SYSTEM}

\subsection{Load Analysis of the Injection Pump}

We now conduct a loading analysis of the injection pump according to the concepts of material mechanics. In the model, the connecting rod between the sealed piston and injection pump is cut off at a position near the bottom of the sealed piston using a cross-section, so that a mechanical model of the injection pump can be established by using the lower plunger and partially-connected suckerrod as the research object.

(1) Upper stroke. As shown in Fig. 4, when the injection pump is in the upper stroke, due to the pressure difference, the lower valve closes and the upper valve opens and begins to inject water into the formation. At this time, the liquid pressure in the plunger ring cavity $\left(p_{c a v}\right)$ is equal to the injection pressure $\left(p_{i n j}\right)$; that is, $p_{c a v}=p_{i n j}$. The liquid pressure in the cavity under the big plunger is equal to the pressure at the injection pump suction port (sinking pressure of the injection pump).

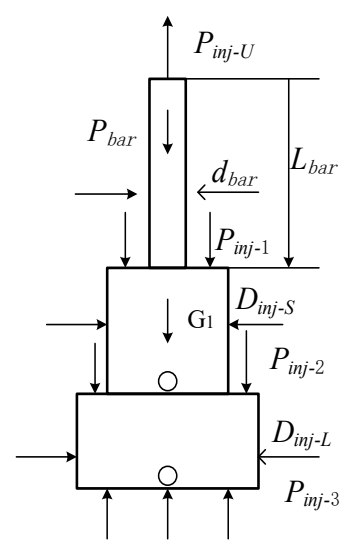

Figure 4 Mechanical analysis of the upper pump stroke

On injection pump:

$$
P_{i n j-U}=P_{b a r}+\frac{\pi}{4}\left(D_{i n j-L}^{2}-d_{b a r}^{2}\right) \cdot p_{i n j}-\frac{\pi}{4} D_{i n j-L}^{2} \cdot p_{i n j-S I}+G_{1}(1)
$$

(2) Down stroke. In the lower stroke of the injection pump, due to a decreasing pressure difference, the lower valve opens, the upper valve closes, the ring chamber between the big and small plungers is in the process of suction, and:

$$
\begin{aligned}
& p_{c a v}=p_{i n j-S I}+p_{T} \\
& P_{i n j-L}=P_{b a r}+\frac{\pi}{4}\left(D_{i n j-S}^{2}-d_{b a r}^{2}\right) p_{i n j-s t o}-\frac{\pi}{4} D_{i n j-L}^{2}\left(p_{i n j-S I}+p_{T}\right)+G_{1}
\end{aligned}
$$

The quid pressure in the plunger ring cavity exerts a downward force on the force and direction of the large plunger, $\mathrm{N}$.

\subsection{Load Analysis of the Sealed Piston}

The short cylinder of the sealed piston is connected between the pumping pump and the bridge packer and the long column plug is connected between the pumping pump and the injection pump so that the up-pumping unit is connected with the down-pumping unit and the injection fluid produced by the injection pump is sealed. In this way, a dynamic seal between the sucker-rod and tubing systems is realized.

As shown in Fig. 5, the pressure on the upper ring is that of the pressure at the pump suction port, and the pressure on the lower end of the ring is that of the injection pump cavity. The upper stroke is equal to the injection pressure and the lower stroke is equal to the stop injection pressure.

(1) Upper stroke. From the static equilibrium equation:

$$
\begin{aligned}
& P_{s p-U}=\frac{\pi}{4}\left(D_{i n j-L}^{2}-D_{s p}^{2}\right) p_{i n j}-\frac{\pi}{4} D_{i n j-L}^{2}\left(p_{i n j-S I}+p_{T}\right)+ \\
& +\frac{\pi}{4}\left(D_{s p}^{2}-d_{s p}^{2}\right)\left(p_{p r o-S L}+p_{T}\right)+P_{b a r}+G_{1}+G_{2}
\end{aligned}
$$

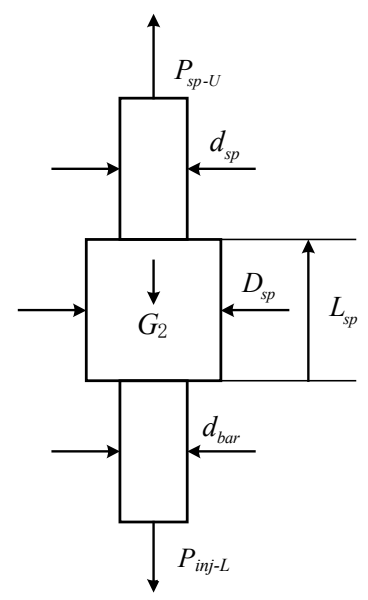

Figure 5 Mechanical analysis of the upper stroke of the sealed piston

(2) Down stroke. From the static equilibrium equation:

$$
\begin{aligned}
& P_{s p-L}=\frac{\pi}{4}\left(D_{i n j-S}^{2}-D_{s p}^{2}\right) p_{i n j-s t o}-\frac{\pi}{4} D_{i n j-S}^{2}\left(p_{i n j-S I}+p_{T}\right)+ \\
& +\frac{\pi}{4}\left(D_{s p}^{2}-d_{s p}^{2}\right)\left(p_{p r o-S L}+p_{T}\right)+P_{b a r}+G_{1}+G_{2}
\end{aligned}
$$

\subsection{Load Analysis of the Production Pump}

To analyse the stresses on the plunger and the upper sucker-rod of the production pump according to material mechanics, the sucker-rod above the production pump was cut off at a position near the production pump plunger using the section method to extract the pump. The lower plunger and some sucker-rods are studied and a corresponding mechanical model is established.

(1) Upper stroke. Fig. 6 shows the production pump in the upper stroke. Due to the pressure difference, the lower valve is closed, the upper valve opens, and the liquid in the ring cavity between the big and small plungers is discharged; that is, $p_{\text {cav }}=p_{\text {dis }}+p_{0}$, and the pressure acting on the lower part of the big plunger is $p_{\text {pro-SL }}+p_{T}$. 


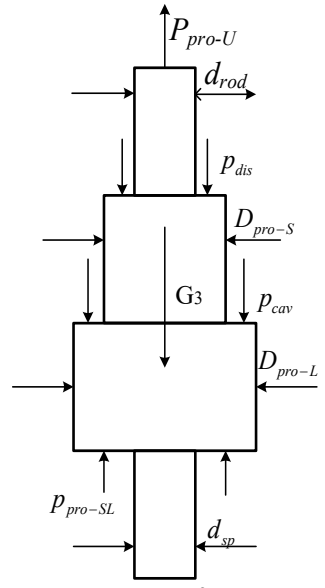

Figure 6 Mechanical analysis diagram of the upper stroke of the production pump

From the static equilibrium equation:

$$
\begin{aligned}
P_{p r o-U}= & \frac{\pi}{4}\left(D_{p r o-L}^{2}-d_{r o d}^{2}\right)\left(p_{d i s}+p_{\mathrm{o}}\right)+\frac{\pi}{4} p_{i n j}\left(D_{i n j-L}^{2}-D_{s p}^{2}\right) \\
& p_{i n j-s t o}-\frac{\pi}{4} D_{p r o-L}^{2}\left(p_{i n j-S L}+p_{\mathrm{T}}\right)+\frac{\pi}{4}\left(D_{s p}^{2}-D_{p r o-L}^{2}\right) \\
& \left(p_{i n j-S L}+p_{\mathrm{T}}\right)+P_{b a r}+G_{1}+G_{2}+G_{3}
\end{aligned}
$$

(2) Down stroke. In the lower stroke, due to the pressure difference, the lower valve opens, the upper valve closes, there is ring suction, and the liquid pressures in the ring cavity and at the pump suction mouth are approximately equal to the sum; that is, $p_{\text {cav }}=p_{\text {pro-SL }}+p_{T}$.

From the static equilibrium equation:

$$
\begin{aligned}
& \left.P_{p r o-L}=\frac{\pi}{4}\left(D_{p r o-S}^{2}-d_{r o d}^{2}\right)\right)\left(p_{d i s}+p_{o}\right)+\left(D_{i n j-L}^{2}-D_{s p}^{2}\right) p_{i n j-s t o}- \\
& -\frac{\pi}{4} D_{p r o-S}^{2}\left(p_{i n j-S L}+p_{T}\right)+\frac{\pi}{4}\left(D_{s p}^{2}-D_{p r o-S}^{2}\right)\left(p_{i n j-S L}+p_{T}\right)+ \\
& +P_{b a r}+G_{1}+G_{2}+G_{3}
\end{aligned}
$$

\subsection{Static Polished Rod Load}

According to the motion and mechanical characteristics of the system:

$$
\begin{aligned}
& P_{j s}=G_{r o d}+P_{p r o-U} \\
& P_{j \mathrm{x}}=G_{r o d}+P_{p r o-L}
\end{aligned}
$$

\section{DYNAMIC ANALYSIS OF ROD STRING IN THE SUCKER-ROD PUMP INJECTION-PRODUCTION SYSTEM}

The sucker-rod pump injection-production system is designed according to a conventional rod pump pumping system. The wave equation in the dynamic model is the same as that in a conventional rod pump pumping system, but the boundary conditions are different. In this section, by establishing and solving a dynamic model of a conventional rod pump pumping system, a numerical solution for the sucker-rod pump injection-production system is obtained.

\subsection{System Dynamics Model}

The dynamic system model consists of partial differential equations and boundary and initial conditions which represent the motion of the rod column. The boundary conditions include the moving condition of the smooth rod and the pumping condition of the downhole pump. In this paper, the differential element method is used to establish the wave equation: at any depth, take the sucker-rod model as shown in Fig. 7(a), and a microelement with a length on it as shown in Fig. 7(b), and analyse the force of the microelement in this segment.

The basic assumptions are as follows:

(1) The liquid density is constant;

(2) A low-slip-rate motor is used and the rotational angular velocity of the crank is constant;

(3) The suction pressure of the sucker pump and the return pressure of the well head are constant;

(4) The vernal resistance of the pump and the friction between the plunger and pump cylinder are not considered.

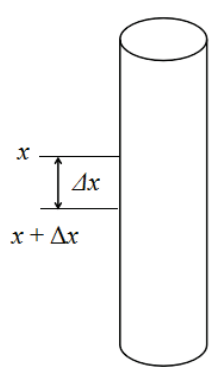

(a)

\section{Figure 7 Microelement force diagram}

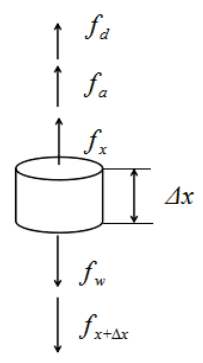

(b)
According to the concept of elasticity, the loads on the microelement include:

Section stress:

$f_{x}=E_{r} A_{r}\left(\frac{\partial u}{\partial x}\right)_{x}$

$f_{x+\Delta x}=E_{r} A_{r}\left(\frac{\partial u}{\partial x}\right)_{x+\Delta x}$

Inertial force:

$f_{a}=\rho_{r} A_{r} \frac{\partial^{2} u}{\partial t^{2}} \Delta x$

Gravity:

$f_{w}=\rho_{r} A_{r} g \Delta x$

Damping force:

$f_{d}=v_{e} \frac{\partial u}{\partial t} \Delta x$

According to the above derivations, the balance principle of force is:

$\sum F_{x}=0$

An equation for the rod column's vibration can be obtained as: 
$E_{r} A_{r}\left[\left(\frac{\partial u}{\partial x}\right)_{x+\Delta x}-\left(\frac{\partial u}{\partial x}\right)_{x}\right]=$

$=\rho_{r} A_{r} \frac{\partial^{2} u}{\partial t^{2}} \Delta x-\rho_{r} A_{r} g \Delta x+v_{e} \frac{\partial u}{\partial t} \Delta x$

The gravity term $\left(\rho_{r} A_{r} g\right)$ is static in a vertical well and does not affect the structure of Eq. (15), so it can be omitted when solving the equation. After simplification, the dynamic model of the sucker-rod pump injectionproduction system can be summarized as follows:

$c^{2} \frac{\partial^{2} u}{\partial t^{2}}=\frac{\partial^{2} u}{\partial t^{2}}+v \frac{\partial u}{\partial t}, 0<x<L, 0<t \leq T$

In the equation:

$c=\sqrt{\frac{E_{r}}{\rho_{r}}}, v=\frac{v_{e}}{\rho_{r} A_{r}}$

The initial conditions are:

$\left.u\right|_{t=0}=\phi(x),\left.\frac{\partial u}{\partial t}\right|_{t=0}=\psi(x), 0 \leq x \leq L$

The boundary conditions are:

$\left.u\right|_{x=0}=\Phi_{1}(t),\left.u\right|_{x=L_{1}}=\Phi_{2}(t),\left.u\right|_{x=L}=\Phi_{3}(t)$,

$0 \leq t \leq T$

In Eq. (19), $\phi(x), \psi(x), \Phi_{1}(t), \Phi_{2}(t), \Phi_{3}(t)$ are known functions determined by the operating conditions of the pumping system.

\subsection{Numerical Analysis of the Dynamic Model}

A dynamic model of the sucker-rod pump injectionproduction system was composed of Eqs. (16), (18) and (19) at the non-boundaries. That is, the respective regions within the rod post above the production pump and above the injection pump are consistent with the dynamic model and the explicit central difference method of the conventional rod pump pumping system. At the interface, the two sucker-rods have different sizes and materials, so the equation coefficients should be altered. Therefore, Eq. (16) should be rewritten to read:

$$
\frac{\partial^{2} u}{\partial t^{2}}=\frac{1}{\rho_{r} A_{r}} \frac{\partial}{\partial x}\left(E_{r} A_{r} \frac{\partial u}{\partial x}\right)-v \frac{\partial u}{\partial t}
$$

In the equation, $v=\frac{\pi v_{d} c}{2 L}, v^{\prime}=\frac{\pi v_{d}}{2 L}$.

Therefore:

$$
\frac{\partial^{2} u}{\partial t^{2}}=\frac{1}{\rho_{r} A_{r}} \frac{\partial}{\partial x}\left(E_{r} A_{r} \frac{\partial u}{\partial x}\right)-v^{\prime} c \frac{\partial u}{\partial t}
$$

In this paper, the solution area is meshed and divided into several rectangular meshes. We take $h_{1}$ and $h_{2}$ as the step sizes in the $x$-direction of the grid, where $h_{1}=L_{1} / n_{1}, h_{2}$ $=L_{2} / n_{2}$, marked with $i$ as the lower foot. We take $\tau$ as the step size in the $t$-direction of the grid, where $\tau=T / m$, marked with $j$ as the lower foot.

The grid coordinates are:

$$
\begin{aligned}
& x=i h_{1}, i=0,1,2, \ldots, n_{1} \\
& x=L_{1}+\left(i-n_{1}\right) h_{2} ; i=n_{1}+1, n_{1}+2, \ldots, n \\
& t=j \tau, j=0,1,2, \ldots, m
\end{aligned}
$$

In the equation: $h_{1}, h_{2}$ and $\tau$ are constants that are greater than zero, and $n=n_{1}+n_{2}$.

The continuous conditions at the production pump position; that is, at the interface between the upper suckerrod of the production pump and the upper sucker-rod of the injection pump, are as follows:

$$
\begin{aligned}
& \left(F_{i, j}\right)_{1}=\left(F_{i, j}\right)_{2}+F_{j} \\
& \left(u_{i, j}\right)_{1}=\left(u_{i, j}\right)_{2}
\end{aligned}
$$

In the equation: $\left(F_{i, j}\right)_{1},\left(F_{i, j}\right)_{2}$ are the dynamic loads at the interface of the production pump upper sucker-rod and injection pump upper sucker-rod $(\mathrm{N})$ and $F_{j}$ is the pump production load $(\mathrm{N})$.

Eq. (25) can be written as:

$$
E_{r} A_{r}\left(\frac{\partial u}{\partial x}\right)_{i 1}=E_{r} A_{r}\left(\frac{\partial u}{\partial x}\right)_{i 2}+F_{j}
$$

According to the Taylor formula, and taking Eq. (26) into account:

$$
\begin{aligned}
& u_{i-1, j}=u_{i, j}-\left(\frac{\partial u}{\partial x}\right)_{i 1} h_{1}+\left(\frac{\partial^{2} u}{\partial x^{2}}\right)_{i 1} \frac{h_{1}^{2}}{2} \\
& u_{i+1, j}=u_{i, j}+\left(\frac{\partial u}{\partial x}\right)_{i 2} h_{2}+\left(\frac{\partial^{2} u}{\partial x^{2}}\right)_{i 2} \frac{h_{2}^{2}}{2}
\end{aligned}
$$

Then, Eqs. (28) and (29) can be obtained:

$$
\begin{aligned}
& \left(F_{i, j}\right)_{1}=E_{r} A_{r}\left(\frac{\partial u}{\partial x}\right)_{i 1}= \\
& =E_{r} A_{r}\left(\frac{\partial^{2} u}{\partial x^{2}}\right)_{i 1} \frac{h_{1}}{2}+E_{r} A_{r}\left(\frac{u_{i, j}-u_{i-1, j}}{h_{1}}\right) \\
& \left(F_{i, j}\right)_{2}=E_{r} A_{r}\left(\frac{\partial u}{\partial x}\right)_{i 2}= \\
& =-E_{r} A_{r}\left(\frac{\partial^{2} u}{\partial x^{2}}\right)_{i 2} \frac{h_{2}}{2}+E_{r} A_{r}\left(\frac{u_{i+1, j}-u_{i, j}}{h_{2}}\right)
\end{aligned}
$$

By using the Taylor series of univariate functions, it can be deduced that: 
$\left(\frac{\partial u}{\partial t}\right)_{i, j}=\frac{u_{i, j+1}-u_{i, j}}{\tau}+O(\tau)$

$\left(\frac{\partial^{2} u}{\partial t^{2}}\right)_{i, j}=\frac{u_{i, j+1}-2 u_{i, j}+u_{i, j-1}}{\tau}+O\left(\tau^{2}\right)$

At the node $(i, j)$, we use Eqs. (32) and (33) to approach $\frac{\partial u}{\partial t}$ and $\frac{\partial^{2} u}{\partial t^{2}}$ separately, then Eq. (16) can be obtained:

$\left(\frac{\partial^{2} u}{\partial x^{2}}\right)_{i 1}=\frac{u_{i, j+1}-2 u_{i, j}+u_{i, j-1}}{\left(c_{1} \tau\right)^{2}}+\left(\frac{v^{\prime}}{c_{1} \tau}\right)\left(u_{i, j+1}-u_{i, j}\right)$
$\left(\frac{\partial^{2} u}{\partial x^{2}}\right)_{i 2}=\frac{u_{i, j+1}-2 u_{i, j}+u_{i, j-1}}{\left(c_{2} \tau\right)^{2}}+\left(\frac{v^{\prime}}{c_{2} \tau}\right)\left(u_{i, j+1}-u_{i, j}\right)$

In the equation: $c_{1}=\sqrt{\frac{E_{r 1}}{\rho_{r 2}}}, c_{2}=\sqrt{\frac{E_{r 2}}{\rho_{r 2}}}$.

Putting Eqs. (30), (30), (34) and (35) into Eq. (25), we obtain:

$\alpha_{1}\left(u_{i, j+1}-2 u_{i, j}+u_{i, j-1}\right)+\beta_{1}\left(u_{i, j+1}-u_{i, j}\right)+$

$+\gamma_{1}\left(u_{i, j}+u_{i-1, j}\right)=-\alpha_{2}\left(u_{i, j+1}-2 u_{i, j}+u_{i, j-1}\right)+$

$+\beta_{2}\left(u_{i, j+1}-u_{i, j}\right)+\gamma_{2}\left(u_{i, j}+u_{i-1, j}\right)+F_{j}$

In Eq. (36): $a=\frac{h E_{r} A_{r}}{2(c \tau)^{2}}, \beta=\frac{h E_{r} A_{r} v^{\prime}}{2 c \tau}, \gamma=\frac{E_{r} A_{r}}{2 \tau}$, where subscripts 1 and 2 represent the sucker-rods at the upper ends of the production and injection pumps, respectively.

According to Eq. (36), the difference equation of the wave equation at the interface between the rod pump and well injection production system is:

$$
\begin{aligned}
& u_{i, j+1}=\left[u_{i, j}\left(2 \alpha_{s}+\beta_{s}-\gamma_{1}-\gamma_{2}\right)-u_{i, j-1} \alpha_{s}+\right. \\
& \left.+u_{i+1, j} \gamma_{2}+u_{i-1, j} \gamma_{1}+F\right] / \alpha_{s}+\beta_{s}
\end{aligned}
$$

In the equation, $a_{s}=a_{1}+a_{2}, \beta_{s}=\beta_{1}+\beta_{2}$.

The dynamic load at the interface is:

$$
\begin{aligned}
& \left(F_{i, j}\right)_{1}=\alpha_{1}\left(u_{i, j+1}-2 u_{i, j}+u_{i, j-1}\right)+ \\
& +\beta_{1}\left(u_{i, j+1}-u_{i, j}\right)+\gamma_{1}\left(u_{i, j}+u_{i-1, j}\right) \\
& \left(F_{i, j}\right)_{2}=-\alpha_{2}\left(u_{i, j+1}-2 u_{i, j}+u_{i, j-1}\right)- \\
& -\beta_{2}\left(u_{i, j+1}-u_{i, j}\right)+\gamma_{2}\left(u_{i, j}+u_{i-1, j}\right) \\
& F_{j}=\left(F_{i, j}\right)_{1}-\left(F_{i, j}\right)_{2}
\end{aligned}
$$

At the non-interface, $\alpha_{1}=\alpha_{2}, \beta_{1}=\beta_{2}, \gamma_{1}=\gamma_{2}, F_{j}=0$, and the equal-step finite difference equation is Eq. (37).

\subsection{Initial and Boundary Conditions}

(1) Initial condition. When the pumping unit is at the lower dead point $(t=0)$, the initial conditions are as follows:

$\phi(x)=0, \psi(x)=0$

The cyclic displacement tolerance conditions are:

$|u|_{t=0}^{(2)}-\left.u\right|_{t=0} ^{(1)} \mid<\varepsilon$

It is also necessary to know that $\left.u\right|_{t=1}$ at the start of the differential calculation can make $\left.u\right|_{t=1}=\left.u\right|_{t=1}$.

(2) Upper boundary condition. The upper boundary conditions can be derived from the geometric motion characteristics of conventional beam pumping units. The solution process can be found in the literature [28]:

$\Phi_{1}(t)=-A \delta_{j}$

\section{(3) Lower boundary condition.}

a. Boundary condition of production pump position

Assuming: 1) We ignore the inertial force of liquid, and 2) we ignore the friction resistance between the plunger and pump cylinder.

Then it can be known that the load on the production pump only contains the static load of the liquid column, that is:

$$
F_{j}=\lambda W_{01}
$$

The above analysis shows that the production pump is similar to a conventional plunger pump, and its theoretical indicator diagram should be a parallelogram. We set the width to $W_{01}$, with a specific shape related to $\lambda$ :

(1) If $F_{j}=0$, and when $u_{n 1, j}-u_{n 1, j-1}>0$ changes to $u_{n 1, j}-u_{n 1, j-1}<0$,

$\lambda=\frac{u_{1}-u_{n 1, j}}{u_{t 1}}$

(2) If $F_{j}=W_{01}$, then $\lambda=1$.

(3) If $F_{j}=W_{01}$, then when $u_{n 1, j}-u_{n 1, j-1}>0$ changes to $u_{n 1, j}-u_{n 1, j-1}>0$,

$\lambda=1-\frac{u_{n 1, j}-u_{1}}{u_{t 1}}$

(4) When $F_{j}=W_{01}$ changes to $F_{j}=0$, then $\lambda=0$.

\section{b. Boundary condition of injection pump position}

In this paper, the following formulas are used to determine the boundary conditions:

$u_{n, j}=\frac{h_{2} p_{t}+2 \beta u_{n-1, j}-\frac{1}{2} \beta u_{n-2, j}}{a h_{2}+\frac{3}{2} \beta}$ 
In the equation, the values of $a, \beta, p_{t}$ can be derived from the working state of the injection pump:

(1) If $\frac{\partial u\left(L_{2}, t\right)}{\partial x}=0$, then $a=0, \beta=1, p_{t}=0$;

(2) If $u\left(L_{2}, t\right)=u_{c}$, and $u_{c}$ is a constant, then $a=1, \beta=0$ and $p_{t}=u_{c}$

(3) If $E_{r} A_{r} \frac{\partial u\left(L_{2}, t\right)}{\partial x}=W_{02}$, then $a=0, \beta=1 \quad$ and $p_{t}=\frac{W_{02}}{E_{r} A_{r}}$.

\subsection{Loads}

(1) Dynamic loads. Dynamic load at the node $(i, j)$ :

$F_{i, j}=E_{r} A_{r}\left(\frac{\partial u}{\partial x}\right)_{i, j}=E_{r} A_{r} \frac{u_{i+1, j}-u_{i-1, j}}{2 h}$

According to Newton's forward interpolation formula:

$$
\begin{aligned}
& \left(\frac{\partial u}{\partial x}\right)_{0, j}=\left(\frac{\partial u}{\partial x}\right)_{1, j}-\frac{1}{2}\left(\frac{\partial u}{\partial x}\right)_{1, j} \times h \\
& \left(\frac{\partial u}{\partial x}\right)_{1, j}=\frac{u_{1, j}-u_{0, j}}{h} \\
& \left(\frac{\partial u}{\partial x}\right)_{2, j}=\frac{u_{2, j}-u_{1, j}}{h}
\end{aligned}
$$

From Eqs. (50) and (51), we obtain:

$$
\left(\frac{\partial^{2} u}{\partial x^{2}}\right)_{0, j}=\frac{\left(\frac{\partial u}{\partial x}\right)_{2, j}-\left(\frac{\partial u}{\partial x}\right)_{1, j}}{h}=\frac{u_{2, j}-2 u_{1, j}+u_{0, j}}{h^{2}}
$$

Taking Eqs. (50) and (52) into Eq. (48), we obtain:

$\left(\frac{\partial u}{\partial x}\right)_{0, j}=\frac{-3 u_{0, j}+4 u_{1, j}-u_{2, j}}{2 h}$

The dynamic load at the suspension point is:

$$
F_{0, j}=\frac{E_{r} A_{r}}{h_{1}}\left(-\frac{3}{2} u_{0, j}+2 u_{1, j}-\frac{1}{2} u_{2 . j}\right)
$$

The dynamic load at the injection pump is obtained using Newton's formula:

$$
\begin{aligned}
& \left(\frac{\partial u}{\partial x}\right)_{n, j}=\left(\frac{\partial u}{\partial x}\right)_{n-1, j}+\frac{1}{2}\left(\frac{\partial u}{\partial x}\right)_{n-1, j} \times h \\
& \left(\frac{\partial u}{\partial x}\right)_{n-1, j}=\frac{u_{n, j}-u_{n-1, j}}{h} \\
& \left(\frac{\partial u}{\partial x}\right)_{n-2, j}=\frac{u_{n-1, j}-u_{n-2, j}}{h}
\end{aligned}
$$

By using Eqs. (56) and (57), we can obtain:

$$
\left(\frac{\partial^{2} u}{\partial x^{2}}\right)_{n-1, j}=\frac{\left(\frac{\partial u}{\partial x}\right)_{n-1, j}-\left(\frac{\partial u}{\partial x}\right)_{n-2, j}}{h}=\frac{u_{n-1, j}-2 u_{n-1, j}+u_{n-2, j}}{h^{2}}
$$

Taking Eqs. (56) and (58) into Eq. (54), we obtain:

$$
\left(\frac{\partial u}{\partial x}\right)_{n, j}=\frac{3 u_{n, j}-4 u_{n-1, j}+u_{2, j}}{2 h}
$$

The dynamic loads of the injection pump are:

$$
F_{n, j}=\frac{E_{r} A_{r}}{h_{2}}\left(\frac{3}{2} u_{n, j}-2 u_{n-1, j}+\frac{1}{2} u_{n-2, j}\right)
$$

The dynamic loads at the interface are (38) and (39) the dynamic load at the interface, respectively.

(2) Static loads. See Section 2 for the corresponding calculations.

\subsection{Condition of Convergence}

$$
\frac{c \tau}{h} \leq 1
$$

When the steps in the $x$-direction of the upper suckerrod of the production pump are different, it should give a minimum of $\tau$.

\subsection{Determination of Damping Coefficient}

Determination of the damping coefficient is very important in solving the dynamic model of the sucker-rod pump injection-production system. In this section, we study the factors influencing the damping coefficient and its calculation theory. Qi's formula based on the equal work principle is adopted to determine the damping coefficient.

The damping work on unit length is:

$$
\begin{aligned}
& \mathrm{d} W=F_{D} \cdot \mathrm{d} u=F_{D} \frac{\partial u}{\partial t} \cdot \mathrm{d} t=v \rho_{r} A_{r}\left(\frac{\partial u}{\partial t}\right)^{2} \mathrm{~d} x \mathrm{~d} t \\
& W=v \rho_{r} A_{r} \int_{0}^{L} \int_{0}^{T}\left(\frac{\partial u}{\partial t}\right)^{2} \mathrm{~d} x \mathrm{~d} t
\end{aligned}
$$

After finishing, the following is obtained:

$$
v=\frac{W}{\rho_{r} A_{r} \int_{0}^{L} \int_{0}^{T}\left(\frac{\partial u}{\partial t}\right)^{2} \mathrm{~d} x \mathrm{~d} t}
$$

According to the friction force formula for A.M.P. unit length, the following results are obtained:

$$
\begin{aligned}
& W=2 \pi\left\{\left[\frac{1}{\ln m}+\frac{4 B_{1}}{B_{2}}\left(B_{1}+1\right)\right] \int_{0}^{L} \int_{0}^{T}\left(\frac{\partial u}{\partial t}\right)^{2} \mathrm{~d} x \mathrm{~d} t+\right. \\
& \left.+\left.\frac{4\left(B_{1}+1\right)}{B_{2}} \int_{0}^{L} \int_{0}^{T} \frac{\partial u}{\partial t}\right|_{x=L} \cdot \frac{\partial u}{\partial t} \mathrm{~d} x \mathrm{~d} t\right\}
\end{aligned}
$$


We then bring it into Eq. (64) so that after simplification, the damping coefficient is as follows:

$$
v=\frac{2 \pi \mu}{\rho_{r} A_{r}}\left[\frac{1}{\ln m}+\frac{4\left(B_{1}+1\right)}{B_{2}}\left(B_{1}+\frac{2}{\frac{\omega L}{c \sin \frac{\omega L}{c}}+\cos \frac{\omega L}{c}}\right)\right]
$$

In the equation:

$$
B_{1}=\frac{m^{2}-1}{2 \ln m}-1, m=\frac{D_{t}}{D_{r}}, B_{2}=m^{4}-1-\frac{\left(m^{2}-1\right)^{2}}{\ln m}, \omega=\frac{\pi n}{30} \text {. }
$$

\section{EXAMPLE MECHANICAL ANALYSIS OF THE ROD STRING IN THE SUCKER-ROD PUMP INJECTION- PRODUCTION SYSTEM}

According to the method mentioned above, the dynamic model of the sucker-rod pump injectionproduction system can be solved, and the dynamic load at any section of the rod column and its corresponding displacement can be obtained. In this section, the total load is the dynamic load plus the static load. In this paper, a simulation program was used for predicting the hanging point indicator diagram and was compiled with the help of Visual Basic language. The hanging point refers to the location of the beam hanger.

(1) Example 1: Well \#1, with a sucker-rod pump injection-production system, is applied in an oil field as an example. The type of equipment used in the well is shown in Tab. 1 and the other production parameters are provided in Tab. 2. Figs. 8 and 9 show the predicted and actual hanging point indicator diagrams, respectively.

\begin{tabular}{|c|c|c|}
\hline \multicolumn{2}{|l|}{ Pumping unit } & CYJY14- 5.5- 89 \\
\hline \multicolumn{2}{|l|}{$Y$} & 76 \\
\hline \multicolumn{2}{|l|}{ Sucker-rod diameter/mm } & 28 \\
\hline \multirow{2}{*}{ Injection pump diameter $/ \mathrm{mm}$} & Large plunger & 83 \\
\hline & Small plunger & 44 \\
\hline \multirow{2}{*}{ Production pump diameter $/ \mathrm{mm}$} & Large plunger & 70 \\
\hline & Small plunger & 57 \\
\hline \multicolumn{2}{|l|}{ Sealed piston $/ \mathrm{mm}$} & 38 \\
\hline
\end{tabular}

Table 1 Equipment type

Table 2 Production parameters of well \#1

\begin{tabular}{|l|c|}
\hline Length of stroke $/ \mathrm{m}$ & 4.21 \\
\hline Frequency of stroke /min & 3.2 \\
\hline Tube pressure $/ \mathrm{MPa}$ & 0.3 \\
\hline Casing pressure $/ \mathrm{MPa}$ & 0.32 \\
\hline Pump depth $/ \mathrm{m}$ & 807.02 \\
\hline Dynamic liquid-level /m & 133.33 \\
\hline Water content $/ \%$ & 84 \\
\hline
\end{tabular}

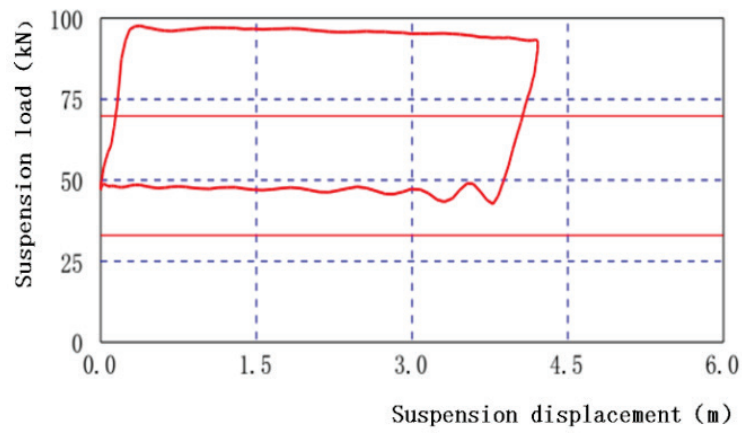

Figure 9 Actual hanging point indicator diagram of well \#1
(2) Example 2: Wells \#2 and \#1 use the same production equipment and the specific production parameters are shown in Tab. 3. Figs. 10 and 11 are the predicted and actual hanging point indicator diagrams, respectively.

Table 3 Production parameters of well \#2

\begin{tabular}{|l|c|}
\hline Length of stroke $/ \mathrm{m}$ & 4.44 \\
\hline Frequency of stroke /min & 2.4 \\
\hline Tube pressure $/ \mathrm{MPa}$ & 0.23 \\
\hline Casing pressure $/ \mathrm{MPa}$ & 0.35 \\
\hline Pump depth $/ \mathrm{m}$ & 744.7 \\
\hline Dynamic liquid-level /m & 212 \\
\hline Water content $/ \%$ & 97.2 \\
\hline
\end{tabular}

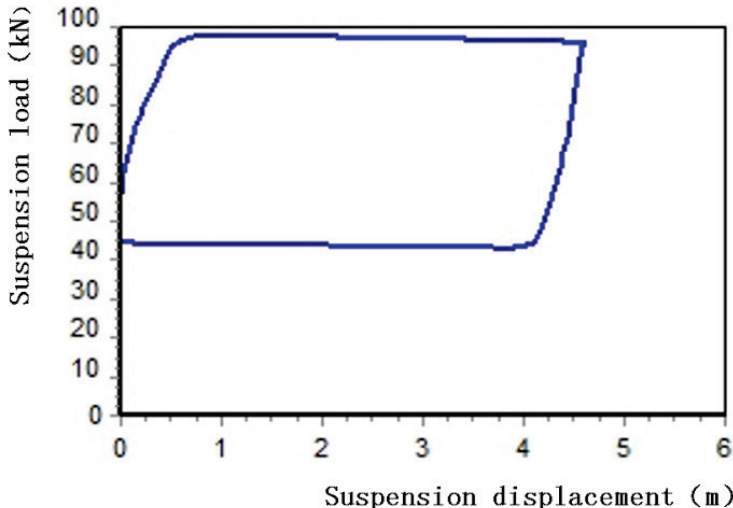

Figure 10 Predicting hanging point indicator diagram of well \#2

Figs. 8-11 shows that the trend of the predicted hanging point indicator curve is the same as that of the actual hanging point indicator curve.

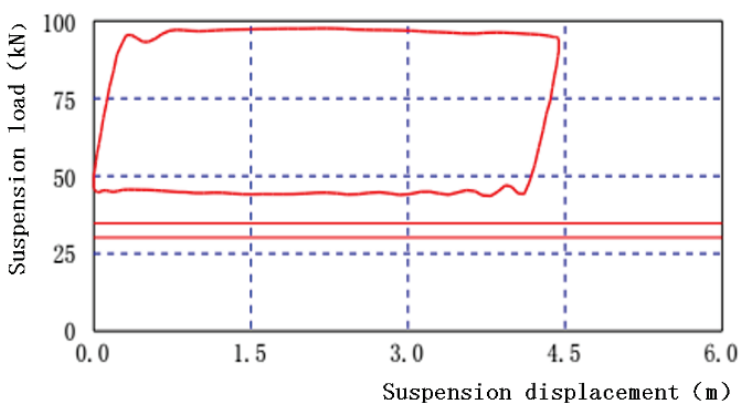

Figure 11 Actual hanging point indicator diagram of well \#2

The corresponding data for wells $\# 1$ and \#2 are compared, as shown in Tab. 4.

It can be seen from the above table that the calculation error of the load is $<3$, which verifies the correctness of the sucker-rod pump injection-production system.

\begin{tabular}{|c|c|c|c|}
\hline \multicolumn{2}{|r|}{ Well number } & $\# 1$ & $\# 2$ \\
\hline \multirow{2}{*}{ Measured data } & Maximum polished rod load $/ \mathrm{kN}$ & 97.81 & 97.61 \\
\hline & Minimum polished rod load $/ \mathrm{kN}$ & 45.9 & 43.55 \\
\hline \multirow{2}{*}{ Estimated data } & Maximum polished rod load $/ \mathrm{kN}$ & 98.5 & 98.89 \\
\hline & Minimum polished rod load $/ \mathrm{kN}$ & 45.68 & 44.72 \\
\hline \multicolumn{2}{|c|}{ Calculation error of maximum load / \% } & 0.7 & 1.3 \\
\hline \multicolumn{2}{|c|}{ Calculation error of minimum load / \% } & 0.5 & 2.7 \\
\hline
\end{tabular}

Table 4 Production parameters of well \#2

\section{CONCLUSIONS}

The sucker-rod pump injection-production system is a new type of oil recovery equipment. It combines production and injection at a single well hole, effectively 
reduces the water cut of the produced liquid, and increases the economic benefit. To ensure the application and popularization of this technique, a mechanical model and its solution was studied. The following conclusions can be drawn:

(1) The structure and working principles of a suckerrod pump injection-production system were introduced and analysed in detail.

(2) Based on the theory of mechanics, a static model of the system was established, and the static loads of the injection pump, sealed piston, and production pump were analysed during the upward and downward strokes.

(3) Based on the theory of elastic mechanics and a mathematical method, a dynamic coupling model of the sucker-rod pump injection-production system was established, and the corresponding explicit difference method was presented.

(4) Using Visual Basic, mechanical simulation and analysis of a rod and column system was conducted based on the model. It was demonstrated that the method can accurately analyse the displacements and loads of a suckerrod string at any section over time, and lays a theoretical foundation for static and dynamic analyses and fault diagnosis in this system.

\section{Acknowledgments}

This work was supported in part by the Natural Science Foundation of China (No. 51774091), the China Postdoctoral Science Foundation (No. 2018T110268) and the Natural Science Foundation of Heilongjiang Province (No. LH2019E018).

\section{Nomenclature}

$P_{i n j-U}$ - Load applied to the upper end of the injection pump during the upward stroke, $\mathrm{N}$

$P_{b a r}-$ Weight of the upper connecting rod, N

$P_{i n j-2}$ - Force of liquid pressure in the plunger ring cavity against the large plunger in the downward direction, $\mathrm{N}$

$P_{i n j-3}$ - Forces acting on the large plunger of the injection pump under the pressure of the liquid produced in the production layer, in the upward direction, $\mathrm{N}$

$G_{1}$ - Injection pump size plunger weight sum, $\mathrm{N}$

$d_{\text {bar }}$ - Sucker-rod diameter, $\mathrm{m}$

$D_{i n j-L}$ - Diameter of injection pump large plunger, $\mathrm{m}$

$D_{i n j-S}$ - Diameter of injection pump small plunger, $\mathrm{m}$

$p_{i n j}$ - Injection pressure, $\mathrm{Pa}$

$p_{T}$ - Casing pressure, $\mathrm{Pa}$

$p_{i n j-S I}$ - Suction pressure of injection pump, Pa

$P_{i n j-L}$ - Load on the upper end of the downstroke injection pump, $\mathrm{N}$

$p_{\text {inj-sto }}$ - Lower stroke injection pump pressure, approximately equal to formation pressure, $\mathrm{Pa}$

$P_{s p-U}, P_{s p-L}$ - Load on upper end of sealed piston in the upper and lower strokes, $\mathrm{N}$

$D_{s p}$ - Sealing piston diameter, $\mathrm{m}$

$d_{s p}$ - Diameter of upper sucker-rod of sealed piston, $\mathrm{m}$

$G_{2}$ - Weight of sealed sucker-rod and sealed piston, N

$L_{s p}$ - Sealed piston length, $\mathrm{m}$

$p_{\text {pro-SL }}$ - Suction inlet pressure, $\mathrm{Pa}$

$P_{\text {pro-U }}$ - Load in the upper stroke of the production pump, N

$D_{\text {pro-L }}$ - Diameter of production pump large plunger, $\mathrm{m}$
$D_{\text {pro-S }}$ - Diameter of production pump small plunger, $\mathrm{m}$ $d_{\text {rod }}$ - Diameter of sucker-rod at the upper end of the production pump, $\mathrm{m}$

$p_{\text {dis }}$ - Production pump discharge pressure, $\mathrm{Pa}$

$p_{c a v}$ - Hydraulic pressure in the ring cavity of the production pump, $\mathrm{Pa}$

$G_{3}$ - Total weight of the production pump plunger, N

$P_{\text {pro-L }}$ - Load on the upper and lower stroke of the production pump, $\mathrm{N}$

$P_{j s}$ - Static load of up-stroke on suspension point, $\mathrm{N}$

$P_{j x}$ - Static load of down-stroke on suspended point, $\mathrm{N}$

$G_{\text {rod }}$ - Weight of rod column at the top of the production pump, $\mathrm{N}$

$f_{x}, f_{x+\Delta x}$ - Internal force on the corresponding section, $\mathrm{N}$

$f_{a}$ - Element inertial force in the opposite direction to the acceleration, $\mathrm{N}$

$f_{d}$ - Viscous damping force per unit length, with a direction opposite to the velocity, $\mathrm{N}$

$f_{w}$ - Unit weight force, $\mathrm{N}$

$\rho_{r}$ - Rod material density, $\mathrm{kg} / \mathrm{m}^{2}$

$A_{x}$ - Column cross-sectional area, $\mathrm{m}^{2}$

$E_{r}$ - Elastic modulus of rod column, $\mathrm{MPa}$

$v_{e}$ - Drag coefficient per unit length, -

$c$ - Velocity of acoustic wave propagation in rod column, $\mathrm{m} / \mathrm{s}$

$L_{1}$ - Length of production pump upper rod column, m

$L_{2}$ - Length of injection pump upper pole, $\mathrm{m}$

$L$ - Sucker-rod total length, m

$u$ - Elastic displacement at any section, $\mathrm{m}$

$x$-Distance from suspension point to any section of the bar column, $\mathrm{m}$

$t$ - Time from start point, $\mathrm{s}$

$v$ - Damping coefficient of well fluid to sucker-rod string

$T$ - Period, s

$A$ - Forearm length of pumping unit, $\mathrm{m}$

$\delta_{j}$ - Swinging angular displacement of beam, rad

$W_{01}$ - Static load of liquid column on production pump, $\mathrm{N}$

$\lambda$ - Coefficient dependent on valve opening/closing state

$u_{1}$ - Displacement of the pump at moment $j-1, \mathrm{~m}$

$u_{t 1}$ - Extension of rod column at production pump, $\mathrm{m}$

$W_{02}$ - Static load on injection pump, $\mathrm{N}$

$D_{t}$ - Sucker-rod diameter, $\mathrm{mm}$

$D_{r}$ - Tubing inner diameter, $\mathrm{mm}$.

\section{REFERENCES}

[1] Han, G. (2008). Study on computational method of the water flooded layer aqueous saturation in high water cut stage. Thesis, Daqing Petroleum Institute, 56-57.

[2] Duan, W. Y. (2009). Experimental Study and Flow Design of Downhole Multi-phase Separation. Thesis, China University of Petroleum, 34-36.

[3] Qu Z. Q., Zhang Q., Li H., etc. (2006). Design of the downhole oil-water separation system for submersible electric pump wells and its ground monitoring model. Journal of Xi'an Shiyou University, 21(3), 34-37. https://doi.org/10.3969/j.issn.1673-064X.2006.03.009

[4] Matthews, C. M., Chachula, R., Peachey, B. R., \& Solanki, S. C. (1996, January). Application of downhole oil/water separation systems in the alliance field. In SPE Health, Safety and Environment in Oil and Gas Exploration and Production Conference. Society of Petroleum Engineers. https://doi.org/10.2118/35817-MS

[5] Chrusch, L. J. (1997). Downhole oil and water separationpotential of a new technology. Proceedings Indonesian 
Petroleum Association Twenty-fifth Silver Anniversary Convention, 10, $72-76$.

[6] Hashmi, K. A. (1996). Application of hydrocyclones for treating produced fluids in heavy oil recovery. Hydrocyclones. Cambridge, 369-382.

[7] Shaw, C. \& Fox, M. (1998). Economics of Downhole Oil/Water Separation: A Case History and Implications for the North Sea. SPE-50618-MS, Society of Petroleum Engineers. European Petroleum Conference, 20-22 October, Hague, Netherlands. https://doi.org/10.2118/50618-MS

[8] Mou, Y. H. (2011). Solving the problem of separating Oil and Water with injection and production Technology in the same well. Technology application, 6(38), 78-80.

[9] Peachey, B. R., Solanki, S. C., Zahaacy, T. A., et al. (1998). Downhole Oil/Water Separation Moves into High Gear. Journal of Canadian Petroleum Technology, 37(7), 34-40. https://doi.org/10.2118/97-91

[10] Allow, K. A. (2013). Hypothetical thermohaline transportation study of pumping-reinjection wells in the geothermal field. Arabian Journal of Geosciences, 6(2), 409417. https://doi.org/10.1007/s12517-011-0360-1

[11] Alexandrel, R. D., Kaya, E., \& Zarrouk, S. J. (2016). Reinjection in geothermal fields - A worldwide review update. Renewable and Sustainable Energy Reviews, 53, 105-162. https://doi.org/10.1016/j.rser.2015.07.151

[12] Kaya, E. (2016). Modelling reinjection into vapourdominated two-phase systems: Part 2 - reinjection experiments on the 3D Model. Geothermics, 60, 196-217. https://doi.org/10.1016/j.geothermics.2015.12.005

[13] Liu, X. P., Wang, Z. B., \& Jin, Y. H. (2007) Application and prospect of downhole oil-water separation technology. Petroleum Machinery, 359(2), 51-53. https://doi.org/10.3969/j.issn. 1001-4578.2007.02.016

[14] Gu, Z. H. \& Shen, L. (2001). Downhole oil-water separation and return injection pump pumping system. Petroleum Machinery, 29(6), 52-54. https://doi.org/10.3969/j.issn.1001-4578. 2001.06.019

[15] Li, D., Zhang, X. J., \& Chen, Y. Y. (2011). Experimental Study on Inlet Structure of the Rod Pump with Down- hole Oil- water Hydrocyclone. Procedia Engineering, 18, 369374. https://doi.org/10.1016/j.proeng.2011.11.059

[16] Bangash, Y. K. (2003). Downhole Oil Water Separation (DOWS) Systems in High-Volume/High HP Application. SPE Latin American and Caribbean Petroleum Engineering Conference, 27-30 April, Port-of-Spain, Trinidad and Tobago. https://doi.org/10.2118/ 81123-MS

[17] Veil, J. A., Langhus, B. G., \& Belieu, S. (1999). DOWS reduce produced water disposal costs. Oil \& Gas Journal, 97(12), 76-85.

[18] Li, J. H. (1999). The downhole oil-water separation technology enters the high speed development stage. Foreign Oilfield Engineering, 5(2), 20-28.

[19] Yan, T. J., Li, Z. L., Wang, H. X., etc. (2000). Design of oilwater separation system for electric submersible pump downhole. Petroleum Machinery, 28(9), 5-7. https://doi.org/10.3969/j.issn.1001-4578.2000.09.002

[20] Zhou, X. J. (2000). Design of downhole oil-water separation system and reciprocating double-fluid flow pump. Petroleum Machinery, 28(9), 1-4. https://doi.org/10.3969/j.issn.1001-4578.2000.09.001

[21] Gibbs, S. (1963). Predicting the behavior of sucker-rod pumping systems. Journal of Petroleum Technology, 15(7), 769-778. https://doi.org/10.2118/588-PA

[22] Chac, J. \& Purcupile, J. (2009). A new model for studying oil well pumping installations. SPE Annual Technical Conference and Exhibition. Dallas Texas. https://doi.org/10.2118/16918-MS

[23] Doty, D. \& Schmidt, Z. (1983). An Improved Model for Sucker Rod Pumping. Society of Petroleum Engineers Journal, 23(1), 33-41. https://doi.org/10.2118/10249-PA
[24] Ferrigno, E. \& Zabala, J. (2015). Pumping unit gearbox torque determination method based on motor behavior. 2015 SPE Artificial Lift Conference - Latin America and Caribbean, 593-598. https://doi.org/10.2118/173982-MS

[25] Lao, L. M. \& Zhou, H. (2016). Application and effect of buoyancy on sucker rod string dynamics. Journal of Petroleum Science and Engineering, 146, 264-271. https://doi.org/10.1016/j.petrol.2016.04.029

[26] Xing, M. M. (2016). Response analysis of longitudinal vibration of sucker rod string considering rod buckling. Advances in Engineering Software, 99, 49-58. https://doi.org/10.1016/j.advengsoft.2016.05.004

[27] Feng Z. M., Tan J. J., \& Sun Y. A. (2018). 3D-Dynamic Modelling and Performance Analysis of Service Behavior for Beam Pumping Unit. Mathematical problems in engineering, 2018, 1-7. https://doi.org/10.1155/2018/9205251

[28] Cui Z. H., Yu G. (1994). Rod pumping system. Beijing: Petroleum Industry Press.

\section{Contact information}

\section{Jiang MINZHENG}

School of Mechanical Science and Engineering,

Northeast Petroleum University,

Daqing, China, 163318

E-mail: jmz1963@126.com

Zhang DESHI (Corresponding Author)

School of Mechanical Science and Engineering,

Northeast Petroleum University,

Daqing, China, 163318

E-mail: 540994586@qq.com

Feng ZI-MING (Corresponding Author)

School of Mechanical Science and Engineering,

Northeast Petroleum University,

Daqing, China, 163318

E-mail: xueyuanfzm@163.com

\section{Duan TIANYU}

Daqing Oilfied Tianyu Engineering Design Co., LTD,

Daqing, China, 163712

E-mail:1509922657@qq.com

\section{Appendix}

Table 5 Structural parameters of pumping unit

\begin{tabular}{|l|c|}
\hline \multicolumn{1}{|c|}{ Construction parameter } & Value \\
\hline Type of sucker-rod pump & CYJY14-5.5-89HF \\
\hline Fore-arm length $/ \mathrm{mm}$ & 5500 \\
\hline Back-arm length $/ \mathrm{mm}$ & 3162 \\
\hline Link-bar length $/ \mathrm{mm}$ & 5300 \\
\hline Horizontal distance $/ \mathrm{mm}$ & 4100 \\
\hline Radius of crank $/ \mathrm{mm}$ & $1440 ; 1240 ; 1020$ \\
\hline Centre height of support $/ \mathrm{mm}$ & 8250 \\
\hline Crank radius $/ \mathrm{mm}$ & 1310 \\
\hline Crank weight $/ \mathrm{kN}$ & 1.096 \\
\hline Transmission ratio & 39.69 \\
\hline Direction of crank rotation & Clockwise \\
\hline Structural imbalance weight $/ \mathrm{kN}$ & 1.2 \\
\hline
\end{tabular}

